\title{
Construção e dissolução da conjugalidade: padrões relacionais
}

\author{
Terezinha Féres-Carneiro ${ }^{1}$ \\ Pontificia Universidade Católica do Rio de Janeiro, Rio de Janeiro-RJ, Brasil \\ Orestes Diniz Neto \\ Universidade Federal de Minas Gerais, Belo Horizonte-MG, Brasil
}

\begin{abstract}
Resumo: O objetivo deste trabalho é realizar uma revisão dos principais estudos que introduziram novas metodologias de investigação sobre padrões de formação e dissolução da conjugalidade, como um processo interacional. A perspectiva sistêmica é adotada epistemologicamente como crivo de análise, por favorecer um campo de diálogo, diferenciando a complexidade dos olhares sobre a conjugalidade. Foram consultados trabalhos publicados até agosto de 2009, e a primeira referência encontrada data de 1938. As bases de dados consultadas foram PsycINFO e SciELO, utilizando-se as seguintes palavras-chave, em múltiplas combinações, em português e inglês: revisão; terapia de casal; conjugalidade; divórcio; interacão. Os estudos citados nos artigos de revisão como inovadores, teórica e metodologicamente, e seus desdobramentos foram destacados, delineandose ênfases temáticas em seu desenvolvimento histórico. São apontadas repercussões para a prática clínica, estratégias para intervenções terapêuticas, bem como os limites desta revisão conceitual.
\end{abstract}

Palavras-chave: métodos de pesquisa, casamento, psicoterapia, divórcio.

\section{Relational patterns of the construction and dissolution of conjugality}

\begin{abstract}
The goal of this work is to conduct a literature review of the main studies that had introduced new methodologies for investigating patterns of construction and dissolution of conjugality as an interactional process. Systemic perspective is epistemologically adopted as a criterion for analysis, because it enables a space for dialogue, differentiating the complexity of the views on conjugality. Studies published until August 2009 were consulted; the first reference found on the topic is from 1938. Databases consulted were PsycINFO and SciELO, using the following key-words (in different combinations of Portuguese and English): review, couples' therapy, conjugality, divorce, and interaction. The studies cited in the articles as theoretic and methodologically innovative, as well as their ramifications, were highlighted, outlining thematic emphasis in its historical development. Repercussions for the clinical practice, strategies for therapeutic interventions and the limits of the conceptual review were pointed out.
\end{abstract}

Keywords: research methods, marriage, psychotherapy, divorce.

\section{Construcción y disolución de la conyugalidad: patrones relacionales}

Resumen: El objetivo de este trabajo es realizar una revisión de los principales estudios que introdujeron nuevas metodologías de investigación sobre patrones de formación y disolución de la conyugalidad como un proceso interactivo. La perspectiva sistémica es adoptada epistemologicamente como prisma de análisis, por favorecer un campo de diálogo y diferenciar la complejidad de miradas sobre la conyugalidad. Han sido analizados artículos publicados hasta el agosto del 2009, teniendo la primera referencia la fecha del 1938. Las bases de datos utilizadas han sido PsycINFO y SciELO, empleando las palabras clave en múltiples combinaciones, en portugués e inglés: revisión; terapia de pareja; conyugalidad; divorcio; interacción. Los estudios mencionados en los artículos de revisión como innovadores, teórica y metodológicamente, y sus derivados han sido destacados, dibujando enfasis temáticas en su desarollo histórico. Se evidencian repercusiones hacia la práctica clínica, estrategias para intervenciones terapéuticas, bien como los limites de esta revisión conceptual.

Palabras clave: métodos de investigación, matrimonio, psicoterapia, divorcio.

O estudo da conjugalidade produziu uma literatura significativa para a compreensão da dinâmica conjugal, adotando diversos enfoques, fornecendo teorias e contribuições às abordagens e modelos terapêuticos. Alguns pontos têm-se destacado nestas pesquisas, com implicações para a prática clínica, especialmente quanto à estabilidade e satisfação conjugal. Assim, o objetivo deste trabalho é analisar, a partir da perspectiva sistêmica, os estudos sobre padrões de formação e dissolução da conjugalidade, como um processo

\footnotetext{
${ }^{1}$ Endereço para correspondência:

Terezinha Féres-Carneiro: Rua General Góes Monteiro, n. 8. Bloco D, apto

2403. Rio de Janeiro-RJ. CEP 22.290-080.E-mail: teferca@puc-rio.br
}

interacional, apontando algumas implicações de tais investigações para os construtos de satisfação/insatisfação, de estabilidade/instabilidade e suas repercussões na prática clínica. Esta abordagem epistemológica reflete a compreensão dos processos psicossociais, como o conjugal, em uma visão marcada pelo olhar da complexidade, que não é onisciente, pois sabe que sempre está referido ao conhecimento local, situado em um momento. Assim, adota-se o caminho possível da construção de meta-pontos de vista, limitados e frágeis, requisito que diferencia o pensamento simples, que acredita em verdades como realidades independentes do observador, e o conhecimento complexo, no qual o observador é introduzido por sua própria conceituação. Como Bong, Crepaldi e Moré (2008, p. 253) apontam: 
Os sistemas familiares, assim como os sistemas sociais, deixam de ser concebidos como estruturas mecânicas coisificadas e passam a ser compreendidos como sistemas intersubjetivos compostos por agentes conscientes, intencionais que se co-criam a si mesmos e a seu entorno em uma permanente interação comunicativa e construção de significados.

Assim, neste trabalho, são analisados estudos inovadores, que propuseram ou introduziram novas metodologias ou técnicas de investigação, na visão de revisores da história da psicoterapia de casal e família. Uma pesquisa bibliográfica foi realizada no Psycinfo, em agosto de 2009, com a combinação variada das palavras-chave: review ou revisão; couple, marital ou casal; relation ou relacionamento. Foram localizados 180 trabalhos em inglês, sendo 59 revisões da literatura e duas meta-análises. Em português apenas um artigo de revisão foi localizado. Expandindo-se a busca através da SciELO, foram encontrados dois artigos que relacionavam os temas revisão e casal, e o artigo em português, localizado pelo PsycINFO. Estes estudos foram analisados e selecionados quanto à pertinência temática e conceitual. Os trabalhos descritos como inovadores nas revisões dos estudos da conjugalidade são discutidos em termos teórico-metodológicos e epistêmicos em sua implicação para a compreensão da conjugalidade, apontando-se implicações para psicoterapia de casal. O critério de desenvolvimento temático histórico foi seguido como orientador nesta revisão, pois fornece uma compreensão adequada dos contextos nos quais os desdobramento e propostas de novas perspectivas teórico-metodológicas surgiram. Assim o desdobramento metodológico seguiu os construtos de satisfação/insatisfação e estabilidade/instabilidade conjugal.

A formação da conjugalidade, na visão sistêmica, é um processo complexo, envolvendo diversos níveis do relacionamento e contextos que resultam na definição psicossocial de uma relação afetiva estável. Autores de estudos sobre família e casamento, como Berger e Kellner (1964), FéresCarneiro (2008), Féres-Carneiro e Diniz Neto (2008) e Grandesso (2000), abordam a conjugalidade como um processo de construção de uma realidade comum. Cada parceiro, ao se engajar na relação a dois, experimenta uma reconstrução de sua realidade individual, criando referências comuns e uma identidade conjugal. Esta relação é construída a partir de trocas verbais e não verbais entre os parceiros que coordenam suas ações recíprocas no universo social de significado, comprometendo-se com a construção de uma história comum, na qual as mudanças na pauta de ação de um dos cônjuges afeta o outro.

No imaginário social, evoca-se a idéia do casal como um par associado por vínculos afetivos e sexuais de base estável, com um forte compromisso de apoio recíproco, com o objetivo de formar uma nova família incluindo, se possível, filhos. A relação conjugal dá-se, portanto, dentro de um contexto sócio-histórico e também familiar no qual o indivíduo, ao se socializar, internaliza pautas de ações psicossociais complexas. Tais pautas dizem respeito tanto a aspectos do processo de socialização primária quanto a processos secundários. Assim, a relação conjugal tem início com a criação de um território comum, no qual começam a ser compartilhadas experiências que produzem pautas de interação social significativas para o casal, relativizadas pela experiência de construção psicossocial de cada indivíduo. $\mathrm{O}$ aspecto de formação da conjugalidade deve ser visto como contínuo e não meramente envolvendo as fases inicias de engajamento amoroso, pois são os padrões de relacionamento que mantêm a conjugalidade e sua qualidade, ao longo do tempo, permitindo que esta resista às diversas circunstâncias, às mudanças previsíveis e imprevisíveis do ciclo de vida (Féres-Carneiro, 2003; McGoldrick, 1989/1995; Mosmann, Wagner, \& FéresCarneiro, 2006).

Por outro lado, a dissolução da conjugalidade é abordada, na perspectiva sistêmica, como um processo no qual os padrões de manutenção da relação são modificados, até o momento em que a relação não pode ser mais definida, pelos cônjuges, ou pelo menos por um deles, como uma relação conjugal. Assim, a ruptura conjugal pode ser catastrófica, no sentido de que o passar do estado no qual os indivíduos são cônjuges, para o estado no qual não mais se definem assim, é abrupto e descontínuo. Porém, esta mudança envolve um longo e doloroso processo que pode durar muitos anos (Féres-Carneiro, 2003) .

Dois eixos aparecem na literatura, organizando os estudos sobre os processos da dinâmica conjugal, em relação aos processos de formação e dissolução da conjugalidade: o da satisfação/insatisfação conjugal e o da estabilidade/ instabilidade conjugal (Diniz-Neto, 2005). Estes construtos têm um desenvolvimento histórico longo que se fundamenta em descobertas advindas da aplicação de diferentes metodologias, perpassando diversos referenciais teóricos. E, não só têm definido a principal linha de inquirição teórica sobre a conjugalidade, como são respostas a uma demanda social por casamentos estáveis e satisfatórios. Além disto, têm também orientado o estudo de outros construtos relacionados, tais como padrões comunicacionais e manejo de conflitos, que serviriam de marcadores e preditores de seu desenvolvimento (Gottman, 1998; Gottman \& Gottman, 2008). Examinar o desenvolvimento destes estudos sobre a conjugalidade, a partir dos eixos satisfação/insatisfação e estabilidade/instabilidade, permite a compreensão da origem destes conceitos, bem como dos diferentes vieses que têm tomado.

\section{Estudos preliminares sobre a conjugalidade: a psicologia do casal}

Os estudos sobre a conjugalidade desenvolveram-se no século XX, seguindo as tendências metodológicas e teóricas que dominavam o campo da psicologia da época, e acompanhando os paradigmas de pesquisa então dominantes em 
diferentes grupos. A necessidade, no início do século XX, de fundamentar as intervenções terapêuticas foi a principal motivação para a realização destas pesquisas, pois o uso de intervenções baseadas em pouco mais do que bom senso tornava a prática de atendimento a casais precária (Gurman $\&$ Fraenkel, 2002). Pode-se balizar o desenvolvimento dos estudos sobre a conjugalidade no surgimento de diferentes metodologias de pesquisa, refletindo mudanças tanto na concepção teórica da conjugalidade, como no desenvolvimento de técnicas de investigação (Broderick \& Schrader, 1991; Gottman \& Notarius, 2002).

É possível discernir vários momentos nos estudos sobre a conjugalidade, tanto pela pergunta que orientava a pesquisa, como pelo contexto teórico e a metodologia empregada. Estes estudos parecem ter influenciado o desenvolvimento das abordagens de terapia de casal e, reciprocamente, foram também influenciados por elas (Gottman \& Gottman, 2008; Gurman \& Fraenkel, 2002). Durante a primeira metade do século XX, predominavam na psicologia métodos de investigação, influenciados pelo paradigma newtoniano-cartesiano, que focavam as características do indivíduo enquanto um processo monádico. Predominava uma visão individualista da psicologia, e a abordagem terapêutica da questão conjugal era o aconselhamento matrimonial, orientado pelos modelos ainda incipientes de psicoterapia de casal psicanalítica, que possuíam, retrospectivamente, muitas limitações metodológicas e teóricas (Broderick \& Schrader, 1991; Gottman \& Notarius, 2002; Gurman \& Fraenkel, 2002). A pressuposição destas abordagens era de que os fenômenos sociais, como o casamento, seriam resultado dos efeitos das características individuais combinadas. Portanto as perguntas de pesquisas iniciais giravam ao redor de quais características de personalidade ou do indivíduo estariam relacionadas com os casamentos felizes. Os métodos de pesquisa utilizados pressupunham que o individuo é quem poderia dar o melhor relato de suas características. Em decorrência desta suposição, foram utilizados relatos obtidos dos sujeitos sobre sua própria personalidade. Em retrospectiva, tais métodos parecem ingênuos e pouco adequados para responder até mesmo o que propunham. É importante notar que, no início do século XX, métodos mais elaborados tanto quantitativos como qualitativos ainda estavam por se desenvolver e difundir.

A primeira pesquisa publicada sobre conjugalidade aparece, nas referências consultadas, como sendo a do livro de Terman, Butterwiser, Fergunson, Johnson e Wilson, de 1938, que se desenvolvia ao redor da pergunta: "Qual a diferença fundamental entre casais felizes e infelizes?". Seguindo o paradigma da época, estes autores buscaram explicar esta diferença nos traços de personalidade que seriam as causas do sucesso ou insucesso da relação. $\mathrm{O}$ uso ingênuo de auto-relato sobre as suas próprias características era considerado adequado para descrição da personalidade, não sendo encontrado nenhum perfil ótimo de personalidade relacionado com a satisfação conjugal. Nas três décadas seguintes, as pesquisas concentraram-se inteiramente no uso de auto-relatos e análise do funcionamento conjugal, variando ao redor das questões iniciais de Terman, Butterweiser, Ferguson, Johnson e Wilsone (1938), incluindo estabilidade e satisfação conjugal (Hicks \& Platt, 1970). Pouco avanço foi feito nas primeiras décadas, apenas incluindo-se nas pesquisas a avaliação da personalidade de um cônjuge através do relato do outro. Contudo nos estudos posteriores, tornou-se claro que o que se avaliava, de fato, não eram traços de personalidade.

Assim, até a década de 1950, as pesquisas sobre conjugalidade eram realizadas quase inteiramente por sociólogos, para os quais ficava cada vez mais claro que qualquer relação entre as medidas, obtidas por meio dos relatos, tornava-se significativa se houvesse um número suficiente de relatos na pesquisa, revelando a fragilidade metodológica de tais estudos. O uso do mesmo método de avaliação para medir dois diferentes construtos, isto é, conceitos construídos teoricamente e relacionados com dados primários, tende a indicar uma correlação, que pode não aparecer caso sejam utilizados diferentes métodos de avaliação para cada construto (Gottman \& Notarius, 2002). Todavia, estes estudos levaram à descoberta dos dois primeiros fenômenos replicáveis encontrados na pesquisa sobre conjugalidade: 0 efeito halo positivo e negativo. Isto é, em casamentos felizes, os traços da personalidade, na descrição do parceiro, tendem a ser realçados e valorizados, enquanto que nos casamentos infelizes tendem a ser avaliados como prejudiciais e negativamente notados (Gottman \& Notarius, 2002). Descobriu-se, portanto, que não eram os traços de personalidade que estariam relacionados com a satisfação conjugal, mas a percepção do parceiro pelo cônjuge.

Novos estudos sobre a satisfação conjugal começaram a ser realizados à medida que se desenvolveram normas $\mathrm{e}$ testes para as dimensões da conjugalidade. Burguess e Walin (1953) realizaram um estudo longitudinal sobre a satisfação conjugal, descobrindo que para a maior parte dos casais, o início do casamento, logo após a lua de mel, é o período de maior felicidade e satisfação conjugal, ocorrendo a partir daí um declínio lento, firme e considerável. Estudos transversais, por outro lado, apontavam que o relacionamento conjugal tende a se deteriorar a partir do nascimento dos filhos, atingindo o pior momento na meia idade, e começando a melhorar apenas quando os filhos deixam a casa dos pais. Hicks e Platt (1970) em sua revisão afirmam: "Talvez a única e mais surpreendente descoberta destas pesquisas é que crianças tendem a prejudicar mais do que contribuir para a felicidade conjugal" (p. 569). Embora exista muito debate sobre este ponto, a maior parte dos estudos realizados nas décadas de 1980 e 1990, indica que a saída dos filhos dá início, não um período de maior carinho e proximidade, mas um período de estresse e declínio na satisfação conjugal (Belsky \& Kelly, 1994). 


\section{Estudos sobre padrões interacionais e cognição}

Na década de 1950, uma importante mudança paradigmática ocorreu com a publicação do trabalho de Bateson, Jackson, Haley e Weakland (1956) sobre o duplo-vínculo, situação em que o padrão de comunicação é paradoxal, e os comunicantes têm um alto nível de envolvimento. Diante das injunções paradoxais o receptor das mensagens não pode abandonar o campo de interação. Nesta situação a resposta só pode ser paradoxal. Tal condição constitui-se num padrão interacional que se repete. A postulação da teoria do duplovínculo pode ser considerada como o início da perspectiva interacional, com importantes consequências para a pesquisa acerca da conjugalidade. A pergunta mudou para: quais padrões de interação estão presentes em casais funcionais, e quais nos disfuncionais? Os padrões disfuncionais poderiam agora ser observados, assim como seu impacto comunicacional, pela análise da interação do casal em seus aspectos verbais e não-verbais. Estes padrões teriam importantes implicações no aparecimento dos esquemas de pensamento disfuncional, desordens do pensamento, alteração da afetividade e de comportamentos. A perspectiva interacional focava simultaneamente o comportamento, enquanto comunicação, e a cognição, exigindo métodos observacionais e foco no processo relacional em desenvolvimento (Watzlawick, Beavin, \& Jackson, 1967/1981).

O artigo inicial de Broderick (1971), na revista Journal of Marriage and Family, o primeiro periódico voltado para clínicos e pesquisadores da área, buscou introduzir a perspectiva sistêmica para pesquisadores sociais, marcando a mudança de foco. Ao mesmo tempo, na Psicologia Social uma importante transformação também ocorria com a introdução de estudos com ênfase no aspecto interacional. A obra de Thibaut e Kelly de 1959 já propunha a descrição das interações sociais em termos de uma matriz de trocas de custo e benefício, uma clara referência e inspiração na teoria de jogos. Estes autores propuseram que o repertório de trocas entre duas pessoas pode ser listado e associado a custos e benefícios particulares, definidos pelo relacionamento, possibilitando uma abordagem matemática da relação em andamento. Assim, no final da década de 1960 e início da década de 1970, diversas sugestões, oriundas de observações em situações clínicas, sugeriam o que seria disfuncional no comportamento interacional e na cognição social do relacionamento conjugal.

Na área conjugal, "a leitura de mente" foi identificada pelo grupo do Mental Research Institute, na qual se atribuía ao parceiro percepções, pensamentos, sentimentos e interpretações sem nenhuma base; ou se esperava que ele agisse de uma certa forma, sem nenhuma informação explícita sobre o que se esperava dele (Watzlawick e cols., 1967/1981). Jackson (1968), por outro lado, desenvolveu hipóteses sobre o relacionamento conjugal ao redor do conceito do quid pro quo (do latim: "isto por aquilo"), ou seja, um padrão de trocas comunicacionais no qual cada um dos cônjuges retribui o comportamento do outro com comportamento semelhante, como retaliação.

Diversos pesquisadores apresentaram hipóteses, muitas vezes contraditórias entre si, sobre o que seria disfuncional na relação conjugal. Raush, Barry, Hertl e Swain (1974) apontam como disfuncional a escalada de conflito em discussões, assim como a evitação de discussões ou a manutenção de discussões sobre assuntos triviais (conflito simbólico). A estrutura de dominância na relação conjugal foi considerada por Gottman (1979) como disfuncional, enquanto Kolb e Strauss (1974) consideravam que a disfuncionalidade estava na ausência da mesma. Algumas outras hipóteses relacionavam-se a aspectos comunicacionais, como a "leitura de mente", ou ao fato de supor e atribuir ao cônjuge motivos ou comportamentos (Watzlawick e cols., 1967/1981), ou à incapacidade de meta-comunicar (Bateson e cols., 1956). Outras hipóteses relacionavam-se a aspectos intrapsíquicos como a projeção dos conflitos internos (Scharff \& Scharff, 1991) e a neurose familiar primária (Meissner, 1978). Muitas destas proposições foram refutadas em estudos controlados, e algumas se revelaram fecundas, enquanto outras ainda não foram suficientemente pesquisadas (Gottman, 1998).

Na década de 1970, duas abordagens pareciam promissoras no estudo da conjugalidade; o estudo dos padrões interacionais e a cognição social sobre a própria interação. Em 1974, Raush e cols. utilizaram ambas as perspectivas em um estudo longitudinal, através da transição para a paternidade. Usando situações de conflito improvisadas e avaliando-as, através de uma forma de análise seqüencial fundamentada na teoria de informação multivariada, obtiveram um padrão de interação que sugeria um esquema cognitivo associado. Propuseram uma meta-teoria, o probabilismo adaptativo, que pretendia ser uma mudança de uma visão determinista do comportamento interativo para uma probabilística. Porém, não utilizaram um método separado para estudar as matrizes de custo benefício, empregando, em vez disto, jogos interativos.

Pesquisas utilizando-se de padrões interacionais semiestruturados, os jogos interativos, foram desenvolvidas em alguns estudos para observar as matrizes de custo beneficio nas interações conjugais (Gergen, 1969; Ravich, Deuth, \& Brown, 1966; Strauss \& Tallman 1971). Contudo, o comportamento possível dos cônjuges, nestes estudos, era tão restrito que os pesquisadores tendiam a não detectar os padrões da interação do casal em outras situações, sendo, portanto, de limitada validade (Gottman \& Notarius, 2002). A ausência de correlação entre a situação nestes jogos e a interação do casal também sugeria que muitos casais com dificuldades eram muito competentes na comunicação e negociação de soluções de conflito, mas que simplesmente não o faziam nas situações conjugais.

Uma das mais importantes conclusões do estudo de Raush e cols. (1974) era de que, quando a interação era observada, a distinção na qual as mulheres seriam mais expressivas e os homens mais instrumentais em seu estilo relacional, 
simplesmente, não se sustentava. Mulheres eram altamente instrumentais e homens usavam de sua expressividade, ou seja, as diferenças de gênero não eram tão claras. Porém, Raush e cols. (1974) concluíram que durante a gravidez, de fato, as mulheres tornam-se mais coercitivas e os homens mais conciliatórios, mas tal diferença desaparecia com o nascimento do bebê.

Tannen (1990) e Ariés (1976), ao tratar das diferenças de linguagem entre homens e mulheres, no local de trabalho, nunca sustentaram que a predominância do estilo instrumental para os homens e do estilo expressivo para as mulheres, ocorreria também nas famílias e nas interações conjugais. Para Gottman e Notarius (2002), a linguagem das mulheres durante um conflito conjugal tende a ser forte, assertiva, persuasiva, dura e definitiva, questionando a qualidade da relação conjugal. Pesquisas norte-americanas indicam que as mulheres começam ao redor de $80 \%$ das discussões conjugais e, normalmente, não são reticentes quanto à apresentação do problema, a suas conseqüências ou a como gostariam de vê-lo solucionado (Ball, Cowan, \& Cowan, 1995). No Brasil, Féres-Carneiro (2003, 2008), dentre outros, também descreve este padrão.

\section{Estudos sobre satisfação conjugal e funcionalidade na família}

Uma importante influência, na emergência da abordagem interacional, foi a teoria geral dos sistemas, de Von Bertalanffy (1968/1977), que estimulou clínicos e pesquisadores a abordar as interações sociais e familiares como um padrão geral de interação, que poderia ser compreendido através da perspectiva das propriedades emergentes dos sistemas. Ao propor a Entrevista Familiar Estruturada (EFE), Féres-Carneiro (2005) observou que o diagnóstico familiar deve ser um diagnóstico interacional, que considere a família como sistema homeostático. O sintoma de um membro deve ser considerado um sintoma da patologia familiar. Os padrões disfuncionais familiares seriam, portanto, decorrentes de uma situação sistêmica e não seriam previsíveis a partir das propriedades ou qualidades de cada participante do sistema. $\mathrm{O}$ que a princípio reduziria muito a utilidade de pesquisas sobre traços de personalidade na conjugalidade. Mas o que seria um padrão disfuncional? Os teóricos responderam que seriam os padrões relacionais que impediriam o desenvolvimento saudável, tais como a dupla vinculação (Watzlawick e cols., 1967/1981), a pseudomutualidade (Wynne, Ryckoff, Day, \& Hirsch, 1958), a mistificação (Laing \& Esterson, 1964), dentre outros. O1son (1970), em sua revisão sobre o campo da terapia de casal, observou que estes conceitos foram desenvolvidos a partir do estudo de famílias com membros esquizofrênicos e que não possuíam base empírica para serem generalizados para as situações conjugais. Contudo, estas idéias sobre o que era ou não funcional levaram a novas pesquisas sobre a conjugalidade.
Na década de 1970, pesquisadores comportamentais e de psicologia infantil entraram no campo da conjugalidade, equipados com métodos de pesquisas interacionais que permitiam a observação e codificação de complexas interações. Um importante passo foi o uso do método de observação interacional, combinado com o uso de métodos de auto-relatos, uma abordagem quantitativa e qualitativa da relação. Este novo enfoque levou ao estudo do contexto da interação, uma idéia que jamais surgiria da abordagem dos traços de personalidade como independentes. Esses métodos, quando aplicados ao estudo de casais e famílias, levaram a resultados que não confirmaram as hipóteses interativas de disfuncionalidade, baseadas em observações clínicas. De modo geral, as pesquisas mostraram que famílias com problemas não eram caracterizadas por um número maior de mensagens de duplo vínculo, nem tampouco por mensagens contraditórias em níveis verbais e não-verbais ou por poucas mensagens metacomunicacionais (Jacob \& Lesin, 1983; Jacob, 1987). Ao invés disto, um grande corpo de evidências suportou a idéia de que famílias com problemas e casais infelizes eram mais negativos emocionalmente, e mais tendentes a serem reciprocamente negativos que famílias e casais felizes (Gottman, 1998; Gottman \& Notarius, 2002). Os dados empíricos da pesquisa interacional sugeriram, nas décadas de 1970 e 1980, uma profunda mudança da perspectiva original de interpretação da teoria geral dos sistemas de um foco nos aspectos de mensagens e feedback cibernéticos da primeira ordem, para a importância do afeto e da subjetividade. O terapeuta de família e casal, ao invés de ser um engenheiro cibernético, deveria ser um ser emocionado, capaz de viver e interagir emocionalmente com seus clientes. Contudo, infelizmente, como apontam Gottman e Notarius (2002, p. 165): "Poucos pesquisadores e terapeutas estavam muito interessados no estudo sobre a emoção, nem eram conhecidos por pesquisar emoções".

Talvez a maior exceção seja o modelo de terapia focada na emoção de Greenberg e Johnson (1988), porém, o estudo sobre as emoções convidou à focalização de pesquisas em aspectos do relacionamento conjugal, satisfação, estabilidade, e acerca do funcionamento do sistema nervoso autônomo e endócrino, revelando insuspeitadas relações. De fato, descobriu-se que o mais importante preditor de longevidade, saúde e doenças é a qualidade das relações íntimas, particularmente das amizades e da relação conjugal. São os padrões emocionais que permitem essa predição e compreensão da correlação (Berkman \& Breslow, 1983; Berkman \& Syme, 1979; Friedman, Tucker, Schwartz, \& Tomilson, 1995). Apesar da importância da emoção no relacionamento conjugal, a mesma tem sido negligenciada. Os estudos atuais sobre conjugalidade têm como tendência focalizar os aspectos sociais e aqueles ligados à cognição. Porém, a importância dos afetos não pode ser negada, pois, mesmo no mais puro estudo de processo de atribuição de causalidade, as emoções intervêm nos resultados. Assim, nas pesquisas, o que é interpretado como uma distorção do processo cognitivo é o efeito emocional do sofrimento conjugal, o que parece ser 
uma redescoberta do efeito halo, que acompanha casamentos felizes ou infelizes (Gottman \& Notarius, 2002).

Outro conceito do estudo de relações sociais, aplicado ao estudo de casais, é o de poder, embora tenha se mostrado de difícil aplicação. Broderick (1993) resumiu, em sua revisão, sua posição sobre o tema ao afirmar:

Literalmente centenas de estudos têm sido feitos sobre o poder na família, o que, quem controla, a custo de quem. A questão tem se mostrado complicada e elusiva. Como resultado a literatura acadêmica sobre o poder na família é volumosa, complexa e sempre contraditória (p. 164).

Os estudos sobre poder tendem a se organizar ao redor da noção de conflito como indicativo da presença do poder e de sua disfunção, contudo, é difícil, em situações observacionais com métodos etológicos, descrever padrões de interação conflitivos e suas conseqüências. Outras abordagens para o estudo do poder tendem a focar padrões de troca relacional com tomadas de decisão, uso de recursos da família, diálogos, coalizão, alianças na família. Contudo os resultados destes estudos são contraditórios, podendo ser encontrados, na literatura sobre o assunto, estudos com conclusões opostas sobre o mesmo aspecto (Broderick, 1993).

O estudo dos afetos, como padrão de controle e influência recíproca, é outra direção de pesquisa surgida a partir da proposta de um modelo matemático teórico feito por Rapport (1960, 1972). A idéia básica desta abordagem é definir o poder em termos da habilidade, em que o afeto de uma pessoa teria de alterar os sentimentos de outra. Esse desenvolvimento pode ser visto como uma reaproximação da proposta inicial de Von Bertalanffy (1968/1977) que propunha o uso de modelos matemáticos para descrição de sistemas. O modelo proposto por Rapport $(1960,1972)$ utilizava-se de equações lineares, e, de modo problemático, não apontava como realizar medições para sua aplicação, podendo ser considerado apenas como um estudo teórico.

\section{Estudos sobre a conjugalidade}

Em outros aspectos, a década de 1970 assistiu a uma grande onda de estudos e desdobramentos teóricos no campo da conjugalidade. As pesquisas mostravam relevantes desdobramentos na avaliação da importância do estudo dos gêneros e de padrões interacionais conjugais, assim como do uso de técnicas observacionais, com grande atenção para as questões metodológicas (Spanier \& Lewis, 1980). O estudo da violência na relação conjugal, iniciado na década de 1960, e que tendia a ver o fenômeno como raro e relacionado apenas a pessoas mentalmente perturbadas ou de baixa classe social, revelou a violência nas famílias e casais. Este fenômeno, pela sua complexidade, mostrou não ser explicável somente em termos de fatores psicológicos individuais ou sociais.
Diferenças culturais e de raça começaram a ser estudadas. Grupos familiares e casais minoritários (famílias monoparentais, casais gays, de lésbicas e de transexuais) começaram a ser reconhecidos como objeto legítimo de estudo, valorizados em sua especificidade e não mais vistos como anomalias (Gottman \& Notarius, 2002). Os fenômenos do divórcio, do abandono, do recasamento (Macklin, 1980), e de famílias de idosos (Streib \& Beck, 1980) receberam atenção.

Na década de 1980, a satisfação conjugal continuava a ser um tópico de estudo, com o aumento de pesquisas longitudinais e amostras maiores e mais representativas (Gottman $\&$ Notarius, 2002). Estudos referentes a revisões sobre diversos temas permitiram a formação de teorias sobre o ciclo de vida familiar, como enquadre para compreensão dos processos envolvendo famílias e casais (Stern-Peck \& Manocherian, 1989/1995). Assim, muitos pesquisadores engajaram-se no estudo dos padrões ligados à transição dos casais através dos ciclos de vida familiar. As perguntas fundamentais eram: como os casais interagem nestes ciclos e qual o efeito desta interação sobre a conjugalidade?

Muitos dos avanços e descobertas sobre estes pontos vieram do desenvolvimento de novas tecnologias e métodos de pesquisa que possibilitaram abordar os aspectos interacionais. O estudo da interação teve importantes desdobramentos com a introdução do uso de videotapes e de computadores na análise de padrões comunicacionais. A combinação destas tecnologias permitiu a sincronização de dados fisiológicos com a interação em andamento, a observação da interação entre esposos, e o uso de playback, tornando possível sincronizar dados sobre a percepção e a cognição dos cônjuges sobre a interação. Assim, a tecnologia viabilizou o estudo, de modo sincronizado, da dinâmica do jogo relacional entre comportamento, cognição, fisiologia e contexto social. As pesquisas revelaram um importante fato:

Pesquisadores descobriram que o estudo isolado do comportamento, cognição ou fisiologia, sem o cuidadoso estudo de suas interdependências, iria severamente limitar sua possibilidade de mapear descobertas sobre o mundo interacional real dos casais estudados (Gottman \& Notarius, 2002, p. 168).

Avanços no estudo de casais também foram realizados com o desenvolvimento de metodologias de codificação de padrões interacionais para avaliação da interação em andamento. Foram desenvolvidos diversos sistemas de codificação em diferentes níveis de complexidade. Inicialmente foram propostos códigos de microanálise que, contudo, revelaram pouco alcance e utilidade em pesquisas sobre construtos ligados à conjugalidade (Gottman \& Notarius, 2002). Grande interesse foi dado ao desenvolvimento de sistemas de codificação global com o objetivo de melhor descrever os padrões de interação em andamento (Floyd, 1989). Sistemas de codificação foram desenvolvidos como o Clínican Rating of Adult Communication (CRAC) proposto por Basco, 
Birchler, Kalal, Talbot e Slater (1991), dentre muitos outros. Comparações realizadas entre os primeiros sistemas de codificação macroscópicos encontraram usualmente convergência moderada (Belanger, Sauborin, Laughrea, Dulude, \& Wright, 1993), o mesmo ocorrendo nas comparações entre codificação macroscópicas e microscópicas (Julien, Markman, \& Lindahl, 1989). Como alternativa a esta situação, Heyman, Eddy, Weiss e Vivian (1995) propuseram um método para o desenvolvimento de categorias mais globais a partir de uma análise fatorial. Usando vídeo tapes de 950 casais em interação conflitiva, analisados através de um método microanalítico, o Marital Interaction Coding System - MICS (Weiss \& Tolman, 1990), os autores encontraram fatores salientes que eram: hostilidade, discussão construtiva de problemas, humor e discussão responsável. Esta análise revelou importantes diferenças com sugestões de códigos globais derivados do MICS (Weiss \& Tolman, 1990).

Um método alternativo de codificação foi proposto por Gottman e Levenson (1992). Este inclui análise de expressões faciais, através do Emotion Facial Action Coding System - EMFACS (Ekman \& Friesen, 1978), uso do MICS em uma versão de codificação mais rápida, o Rapid Couples Interaction Scoring System - RCISS (Krokoff, Gottman, \& Hass, 1989), e um código de análise de expressão afetiva o Specific Affect Coding System - SPAFF (Gottman, McCoy, Coan, \& Colier, 1996), delineando expressões em nível macroscópico de raiva, tristeza, medo. A grande precisão deste método permitiu a descoberta do único preditor efetivo de estabilidade e satisfação conjugal, para casais pré-conjugais com até quatro anos de relação, ou seja, a intensidade de afeto positivo entre os noivos (Gottman, Coan, Carrere, \& Sawnson, 1998).

Griffin (1993) propôs um método que permite o estudo de como um evento, na história do casal, pode ser utilizado para estudar as avaliações subjetivas das interações entre os cônjuges. Os casais, neste experimento, tinham duas conversações sucessivas, gravadas. A primeira sobre uma memória agradável e a segunda sobre um conflito. A seguir, eram convidados a assistir à interação e avaliar seus sentimentos durante os eventos, em uma escala de afetos, momento a momento. A auto-avaliação foi utilizada como foco do estudo. O autor descobriu que as esposas mantinham um estado negativo de afeto por mais tempo que os maridos, em relação ao problema conjugal em foco. O tempo de mudança do afeto negativo era determinado pela escolaridade das esposas, pelo seu grau de satisfação conjugal, e duração prévia do afeto negativo. Já, para os maridos, o que os fazia permanecer em um estado emocional negativo era o tempo de vivência no estado negativo durante a interação. Assim, parece que as esposas são mais sensíveis a uma avaliação global do relacionamento conjugal que os maridos, sendo que estes parecem responder mais a interação em andamento.

O desenvolvimento destes métodos contribuiu para o estudo de processos conjugais, relacionando estudos de corte de amostras transversais e construção de hipóteses em pesquisas descritivas, gerando modelos para predição do relacionamento ao longo do tempo. Esses estudos fundamentaram-se na percepção da relação conjugal como um processo, em ciclos desenvolvimentais, com transições previsíveis e contínuas e com rupturas descontínuas (Hoffman, 1989/1995). Assim, pode-se supor que os padrões interacionais que caracterizam o engajamento dos casais, nas diversas fases do ciclo familiar - recém-casados, novos pais, meiaidade, ninho vazio e avós - sejam marcados com qualidades únicas que possibilitam ao casal adaptar-se e enfrentar estas importantes tarefas existenciais (Stern-Peck \& Manocherian, 1989/1995). Pesquisadores interacionais têm buscado mapear os processos críticos que marcam essas passagens desenvolvimentais, demarcando estas transições como a formação e a dissolução da conjugalidade, em diferentes momentos do ciclo de vida familiar, construindo modelos úteis para a prática clínica (McGoldrick, 1989/1995; Stern-Peck \& Manocherian, 1989/1995). Estes modelos necessitam ainda de refinamento, pois, como observam Mosmann, Wagner, \& Féres-Carneiro (2006), existe uma dispersão de conceitos de qualidade na relaçao de casal, relacionados às principais teorias sobre a satisfação conjugal, criando um quadro de complexa interpretação.

\section{Considerações finais: implicações para a prática clínica}

É importante ressaltar que a revisão realizada, ao eleger como foco de pesquisa a interação, deixou de considerar aspectos significativos da dinâmica conjugal, dentre os quais, a construção de significados. Além disto, ao adotar como critério para o levantamento dos dados da pesquisa os eixos satisfação/insatisfação e estabilidade/instabilidade conjugal, outros relevantes temas relacionados à conjugalidade não foram abordados.

Por outro lado, cabe ressaltar também que os estudos interacionais trazem importantes contribuições para a clínica de casais, ao sugerir direções e intervenções. Contudo, em um nível global, o que parece ser necessário é aumentar o afeto positivo e reduzir o negativo nos conflitos conjugais. Dessa forma, pode-se criar um padrão de afetos positivos estabilizadores como objetivo primário. Segundo as pesquisas revistas, este é o padrão básico, por meio do qual os casais podem regular o conflito e, sem ele, em uma discussão, o casal entrará em um padrão de escalada de retaliações negativas (quid pro quo). Assim, é possível reduzir o grau de reciprocidade de afeto negativo, implementando-se mais técnicas de reparação, reduzindo os comentários severos nas discussões, reduzindo a defensividade e aumentando a serenidade. Já os aspectos pré-interacionais também podem e devem ser abordados, reduzindo o início de discussões com comentários severos, substituindo padrões de expressão de desprezo por padrões de admiração e afeto. Quanto aos aspectos interacionais, estes podem também ser trabalhados, levando os casais a responderem à raiva construtivamente, incrementando as conexões emocionais e auxiliando-os a 
entender e valorizar o significado dos objetivos e sonhos dos parceiros. No entanto, sugerir direções de mudanças não é o mesmo que realizá-las. Neste sentido, os estudos interacionais indicam, sobretudo, os marcadores e preditores de relações de casais que, aparentemente, se encontram em padrões funcionais ou não. Um posicionamento teórico-clínico que considere todos estes estudos se faz necessário, possibilitando um leque de opções mais amplo nas intervenções terapêuticas, pois a arte e a ciência da terapia de casal repousam na capacidade que o terapeuta possui de identificar a dinâmica conjugal e ser capaz de interagir no sentido de promover a saúde emocional dos cônjuges. O estudo da conjugalidade, ao focar a dinâmica interacional, pode contribuir para o desenvolvimento de teorias e práticas clínicas mais contextualizadas e fundamentadas.

\section{Referências}

Ariés, E. (1976). Interaction patterns and themes in male, female, and mixed groups. Small Group Behavior, 7, 7-18.

Ball, F. L., Cowan, P., \& Cowan, C. P. (1995). Who's got the power? Gender differences in partners' perceptions of influence during marital problem-solving discussions. Family Process, 34, 303-321.

Basco, M. R., Birchler, G. R., Kalal, B., Talbot, R., \& Slater, M.A. (1991). The clinician rating of adult communication (CRAC): A clinician's guide to the assessment of interpersonal communication skill. Journal of Clinical Psychology, 47, 368-380.

Bateson, G., Jackson, D., Haley, J., \& Weakland, J. (1956). Toward a theory of schizophrenia. Behavioral Science, 1, 251-264.

Belanger, C., Sauborin, S., Laughrea, K., Dulude, D., \& Wright, J. (1993). Macroscopic marital interaction coding systems: Are they interchangeable? Behavior Research and Therapy, 31, 789-795.

Belsky, J., \& Kelly, J. (1994). The transition to parenthood: How a first child changes a marriage: Why some couples grow closer and others apart. New York: Dell Publishing.

Berger R., \& Kellner, E. (1964). Marriage and the construction of reality. Diógenes, 12, 1-24.

Berkman, L. F., \& Breslow, L. (1983). Health and the ways of living: The Alameda County Study. New York: Oxford University Press.

Berkman, L. F., \& Syme, S. L. (1979). Social networks, host resistance, and mortality: A nine-year follow-up study of Alameda County residents. American Journal of Epidemiology, 109, 186-204.

Bong, E., Crepaldi, M. A., \& Moré, C. L. O. (2008). Pesquisa com famílias: Aspectos teórico-metodológicos. Paidéia (Ribeirão Preto), 18, 251-266.

Broderick, C. B. (1971). Beyond the five conceptual frameworks: A decade of development in family theory. Journal of Marriage and Family, 33, 139-159.
Broderick, C. B. (1993). Understanding family process: Basics of family systems theory. Newbury Park CA: Sage Publications.

Broderick, C. B., \& Schrader, S. S. (1991). The history of professional marriage and family therapy. In A.S. Gurman \& D.P. Kniskern, (Orgs.), Handbook of family therapy (pp. 3-40). New York: Brunner/ Mazel.

Burgess, E. W., \& Wallin, P. (1953). Engagement and marriage. Philadelphia: J. B. Lippincott.

Diniz-Neto, O. (2005). Conjugalidade: Proposta de um modelo construcionista social de terapia de casal. Tese de doutorado não-publicada, PUC-Rio, Rio de Janeiro.

Ekman, P., \& Friesen, W. V. (1978). Facial action coding system. Palo Alto: Consulting Psychologists Press.

Féres-Carneiro, T. (2003). Separação: O doloroso processo de dissolução da conjugalidade. Psicologia em Estudo, 8, 367-374.

Féres-Carneiro, T. (2005). Entrevista Familiar Estruturada - EFE: Um método clínico de avaliação das relações familiares. São Paulo: Casa do Psicólogo.

Féres-Carneiro, T. (2008). Pesquisa e prática clínica: Construindo articulações teóricas. Psicologia: Reflexão e Crítica, 21, 349-355.

Féres-Carneiro, T., \& Diniz-Neto, O. (2008). De onde viemos? Uma revisão histórico conceitual da terapia de casal. Psicologia: Teoria e Pesquisa, 24, 487-496.

Floyd, F. J. (1989). Segmenting interactions: Coding units for assessing marital and family behaviors. Behavioral Assessment, 11, 13-29.

Friedman, H. S., Tucker, J. S., Schwartz, J., \& Tomilson, E. (1995). Psychosocial and behavioral predictors of longevity: The aging and death of the "Termites". American Psychologist, 50, 69-78.

Gergen K. J. (1969). The psychology of behavior exchange. Reading MA: Addison-Wesley.

Gottman, J. M. (1979). Marital interaction: Experimental investigations. New York: Academic Press.

Gottman, J. M. (1998). Psychology and the study of marital process. Annual Review of Psychology, 49, 169-197.

Gottman, J. M., Coan, J., Carrere, S., \& Swanson, C. (1998). Predicting marital happiness and stability from newlywed interactions. Journal of Marriage and the Family, 60, 5-22.

Gottman, J. M., \& Gottman, J. S. (2008). Therapy Gottman. In A. S. Gurman (Org.), Clinical handbook of couple therapy (pp. 138-164). New York: Guilford Press.

Gottman, J. M., \& Levenson, R. W. (1992). Marital process predictive of later dissolution: Behavior, physiology and health. Journal of Personality and Social Psychology, 63, 221-233.

Gottman, J. M., \& Notarius, C. I. (2002). Marital research in the 20th century and a agenda for the 21 th century. Family Process, 41, 159-198. 
Gottman, J. M., McCoy, K., Coan J., \& Colier, H. (1996). The speciffic affect Coding System (SPAFF) for observing emotional communication in marital and family interaction. In: J. M. Gottman (Org.), What predicts divorce? The Measures (pp. 112-195). Mahwah: Lawrence Erinbaum Associates.

Grandesso, M. A. (2000). Sobre a reconstrução do significado: Uma análise epistemológica e hermenêutica da prática clínica. São Paulo: Casa do Psicólogo.

Greenberg, L. S., \& Johnson, S. M. (1988). Emotionally focused marital therapy. New York: Guilford Press.

Griffin, W. A. (1993). Event history analysis of marital and family interaction: A practical introduction. Journal of Family Psychology, 6, 211-229.

Gurman, A. S., \& Fraenkel, P. (2002). The history of couple therapy: A millennial review. Family Process, 41, 199260.

Heyman, R. E., Eddy, J. M., Weiss, R. L., \& Vivian, D. (1995). Factor analysis of the Marital Interaction Coding System (MICS). Journal of Family Psychology, 9, 209215

Hicks, M. W., \& Platt, M. (1970). Marital happiness and stability: A review of the research in the sixties. Journal of Marriage and Family, 32, 553-573.

Hoffman, L. (1995). O ciclo de vida familiar e a mudança descontínua. In B. Carter \& M. McGoldrick (Orgs.), As mudanças no ciclo de vida familiar (pp. 84-96). Porto Alegre: Artes Médicas. (Original publicado em 1989)

Jackson, D. D. (1968). Therapy, communication and change. Palo Alto: Science and Behavior Books.

Jacob, T. (1987). Family interaction and psychopathology: Historical overview. In T. Jacob (Org.), Family interaction and psychopathology (pp. 37-59). New York: Plenum.

Jacob, T., \& Lessin, S. (1983). Inconsistent communication in family interaction. Clinical Psychology Review, 2, 295-309.

Julien, D., Markman, H. J., \& Lindahl, K. M. (1989). A comparison of a global and a macroanalytic coding system: Implications for future trends in studying interactions. Behavioral Assessment, 11, 81-100.

Kolb, J. M., \& Straus, M. A. (1974). Marital power and marital happiness in relation to problem-solving. Journal of Marriage and the Family, 36, 756-766.

Krokoff, L. J., Gottman, J. M., \& Hass, S. D. (1989). Validation of a global rapid couples interaction scoring system. Behavioral Assessment, 11, 65-79.

Laing, R., \& Esterson, A. (1964). Sanity madness and family. Baltimore: Penguin.

McGoldrick, M. (1995). A união das famílias através do casamento: O novo casal. In B. Carter \& M. McGoldrick (Orgs.), As mudanças no ciclo de vida familiar (pp. 184205). Porto Alegre: Artes Médicas. (Original publicado em 1989)

Macklin, E. D. (1980). Nontraditional family forms: A decade of research. Journal of Marriage and the Family, 42, 905-921.
Meissner W. W. (1978). The conceptualization of marriage and family dynamics from a psychoanalytic perspective. In T. J. Paoline \& B. S. MacCrady (Orgs.), Marriage and marital therapy (pp. 173-197). New York: Bruner Mazel.

Mosmann, C., Wagner, A., \& Féres-Carneiro, T. (2006). Qualidade conjugal: Mapeando os conceitos. Paideia (Ribeirão Preto), 16, 315-325.

Olson, D. H. (1970). Marital and family therapy: Integrative review and critique. Journal of Marriage and Family, 32, 501-538.

Rapport, A. (1960). Fights, games, and debates. Oxford: University of Michigan Press.

Rapport, A. (1972). The uses of mathematical isomorphism in general systems theory. In G. J. Klir (Org.), Trends in general systems theory (pp. 42-77). New York: Wiley Interscience.

Raush, H. L., Barry, W. A., Hertl, R. K., \& Swain, M. A. (1974). Communication, conflict, and marriage. San Francisco: Jossey-Bass.

Ravich, R., Deutch, H., \& Brown, B. (1966). An experimental study of marital discord and decision making. In L. M. Cohen (Org.), Family structure, dynamics and theory (pp. 105-135). Washington DC: American Psychiatric Association, New York.

Scharff D. E., \& Scharff, S. S. (1991). Object relation couple therapy. Northvale: Aronson.

Spanier, G. B., \& Lewis, R. A. (1980). Marital quality: A review of the seventies. Journal of Marriage and Family, 42, 825-839.

Stern-Peck, J., \& Manocherian, J. (1995). O divórcio no ciclo de vida familiar. In B. Carter, \& M. McGoldrick (Orgs.), As mudanças no ciclo de vida familiar (pp. 291320). Porto Alegre: Artes Médicas. (Original publicado em 1989)

Straus, M., \& Tallman, I. (1971). SIMFAM: A technique for observational measurement and experimental study of families. In J. Aldous, T. Condon, R. Hill, M. Straus, \& I. Tallman (Orgs.), Family problem solving (pp. 379-438). Hinesdale: Dryden.

Streib, G. F., \& Beck, R. W. (1980). Older families: A decade review. Journal of Marriage and Family, 42, 937-956.

Tannen, D. (1990). You just don't understand. New York: William Morrow \& Co.

Terman, L. M., Butterweiser, P., Ferguson, L. W., Johnson, W. B., \& Wilson, D. P. (1938). Psychological factors in marital happiness. Stanford CA: Stanford University Press.

Thibaut, J. W., \& Kelley, H. H. (1959). The social psychology of groups. New York: John Wiley \& Sons.

von Bertalanffy, L. (1977). Teoria geral dos sistemas. Petrópolis: Vozes. (Original publicado em 1968)

Watzlawick, P., Beavin, J., \& Jackson, D. (1981). Pragmática da comunicação humana (A. Cabral, Trad.). São Paulo: Cultrix. (Original publicado em 1967) 
Weiss, R. L., \& Tolman, A. O. (1990). The marital Interaction Coding System-Global (MICS-G): A global comparison to the MICS. Behavioral Assessment, 12, 271-294.

Wynne, L. C. Ryckoff, I. M., Day, J., \& Hirsch, S. I. (1958). Pseudo mutuality in the family relationship of schizophrenics. Psychiatry, 21, 205-220.

Terezinha Féres-Carneiro é Professora Titular do Departamento de Psicologia da Pontifícia Universidade Católica do Rio de Janeiro.

Orestes Diniz Neto é Professor Adjunto do Departamento de Psicologia da Faculdade de Filosofia, Ciências e Letras da Universidade Federal de Minas Gerais.

Recebido: 28/08/2009

$1^{a}$ Revisão: 08/01/2010

$2^{a}$ Revisão: $17 / 03 / 2010$

Aceite final: 15/04/2010 